\title{
The itinerary of circulating miRNAs - implications for cancer progression and diagnosis
}

\section{Przemysław Szałata}

Department of Biochemistry and Molecular Biology, Poznan University of Medical Sciences, Poland

(iD) -

\section{Anna-Maria Guner}

Department of Biochemistry and Molecular Biology, Poznan University of Medical Sciences, Poland

(iD) -

\section{Michalina Raczkowska}

Department of Biochemistry and Molecular Biology, Poznan University of Medical Sciences, Poland

(iD) -

\section{Julia Smyrek}

Department of Biochemistry and Molecular Biology, Poznan University of Medical Sciences, Poland

(iD) -

\section{Dominika Szaj}

Department of Biochemistry and Molecular Biology, Poznan University of Medical Sciences, Poland

(D) -

\section{Katarzyna Samelak}

Department of Biochemistry and Molecular Biology, Poznan University of Medical Sciences, Poland

(iD) -

Agnieszka Rybarczyk

Poznan University of Technology, Poland

(iD) -

\author{
Tomasz P. Lehmann \\ Department of Biochemistry and Molecular Biology, \\ Poznan University of Medical Sciences, Poland \\ (iD) https://orcid.org/0000-0001-8445-0970 \\ Corresponding author: tlehmann@ump.edu.pl
}

DOI: https://doi.org/10.20883/medical.e516

Keywords: microRNA, cancer, tumour microenvironment, exosomes, biomarker

Published: 2021-03-30

How to Cite: Szałata P, Guner A-M, Raczkowska M, Smyrek J, Szaj D, Samelak K, Rybarczyk A, Lehmann TP. The itinerary of circulating miRNAs - implications for cancer progression and diagnosis. JMS. 2021 Jun. 28;90(2)2021:e516. doi:10.20883/medical.e516

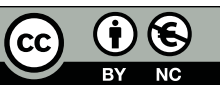

(c) 2021 by the author(s). This is an open access article distributed under the terms and conditions of the Creative Commons Attribution (CC BY-NC) licencse. Published by Poznan University of Medical Sciences

\begin{abstract}
microRNAs (miRNAs) are non-coding RNAs that regulate gene expression and protect cells from foreign nucleic acids. miRNA is produced in the nucleus and processed in the cytoplasm. These small nucleic acid molecules are released from cells to the extracellular matrix (extracellular miRNA, ex-miRNA) and reach blood plasma (circulating miRNA). Circulating miRNA can also be detected in other biological fluids, such as saliva, cerebrospinal fluid or urine, and it is usually carried by proteins or extracellular vesicles. Argonaute-miRNA, or miRNA-lipoprotein complex, protect miRNA from being degraded. The entrance of extracellular miRNA into a target cell is mediated by endocytosis and membrane fusion of extracellular vesicles. Additionally, miRNA can also be delivered in high-density lipoproteins by means of interactions with scavenger receptors. miRNAs absorbed into a cell can act as tumour promoters (oncomirs), or suppressors by inhibiting the translation process of the target mRNAs, thus, affecting cells in the tumour microenvironment. miRNA can impact other cells by supporting tumour growth, promoting angiogenesis and modulating the immune system. Molecular high-throughput methods are employed to detect circulating miRNA, and a potentially helpful diagnostic test has been designed to characterise the cancer type. In this review, we aim to summarise the itinerary of miRNAs from a source cell to a target cell, as well as to show how this class of small nucleic acids participates in intercellular communication. Finally, we highlight examples of miRNAs usage as potential molecular markers and discuss treatment approaches in clinical trials.
\end{abstract}


Abbreviation list:

short interfering RNA - siRNA, microRNA - miRNA, precursor miRNA - pre-miRNA, RNA binding proteins - RBPs, tunnelling nanotubes - TnT, high-density lipoproteins - HDLs, argonaute 2 - Ago2, extracellular vesicles - EV, extracellular microRNA - ex-miRNA, toll-like receptors - TLR, heparan sulfate proteoglycans - HSPGs, heterogeneous ribonuclear protein E2 - hnRNP E2, non-coding RNA - ncRNA, tumour-necrosis factor-a (TNF-a), tumour microenvironment TME, cancer-associated fibroblast - CAF, vascular endothelial cadherin - VE-cadherin, human umbilical vein endothelial cells monolayer HUVEC, polyethyleneimine -PEI.

\section{Synthesis and release of miRNA molecules into the intercellular space}

\section{1. miRNA synthesis}

Different types of small RNAs, including miRNAs, tRNAs, rRNAs and yRNAs (YRNAs - small non- coding RNAs essential for the initiation of chromosomal DNA replication), have been detected in the extracellular matrix and circulation [1]. In the last decades, small RNAs have gained new significance as regulators of eukaryotic genomes. Mature miRNA is a single-stranded RNA derived from a double-stranded precursor with 20-22 base pairs in length. It regulates gene expression and defends cells against invasive extracellular nucleic acids, and recent research proves its diversity in terms of biogenesis pathways and regulatory mechanisms [2]. Furthermore, miRNAs are the most broadly distributed in both phylogenetic and physiological terms, therefore, we will focus on these molecules, as since they are secreted and absorbed by cells, they could therefore be considered as signalling molecules.

The biogenesis of miRNA constitutes a multistage process in which both nuclear and cytoplasmic enzymes have been addressed in a number of reviews, e.g. Bartel (Figure 1) [2]. According to the studies, miRNAs could regulate gene expression in the cell, or could be exported to the extracellular matrix by means of extracellular vesicles [1]

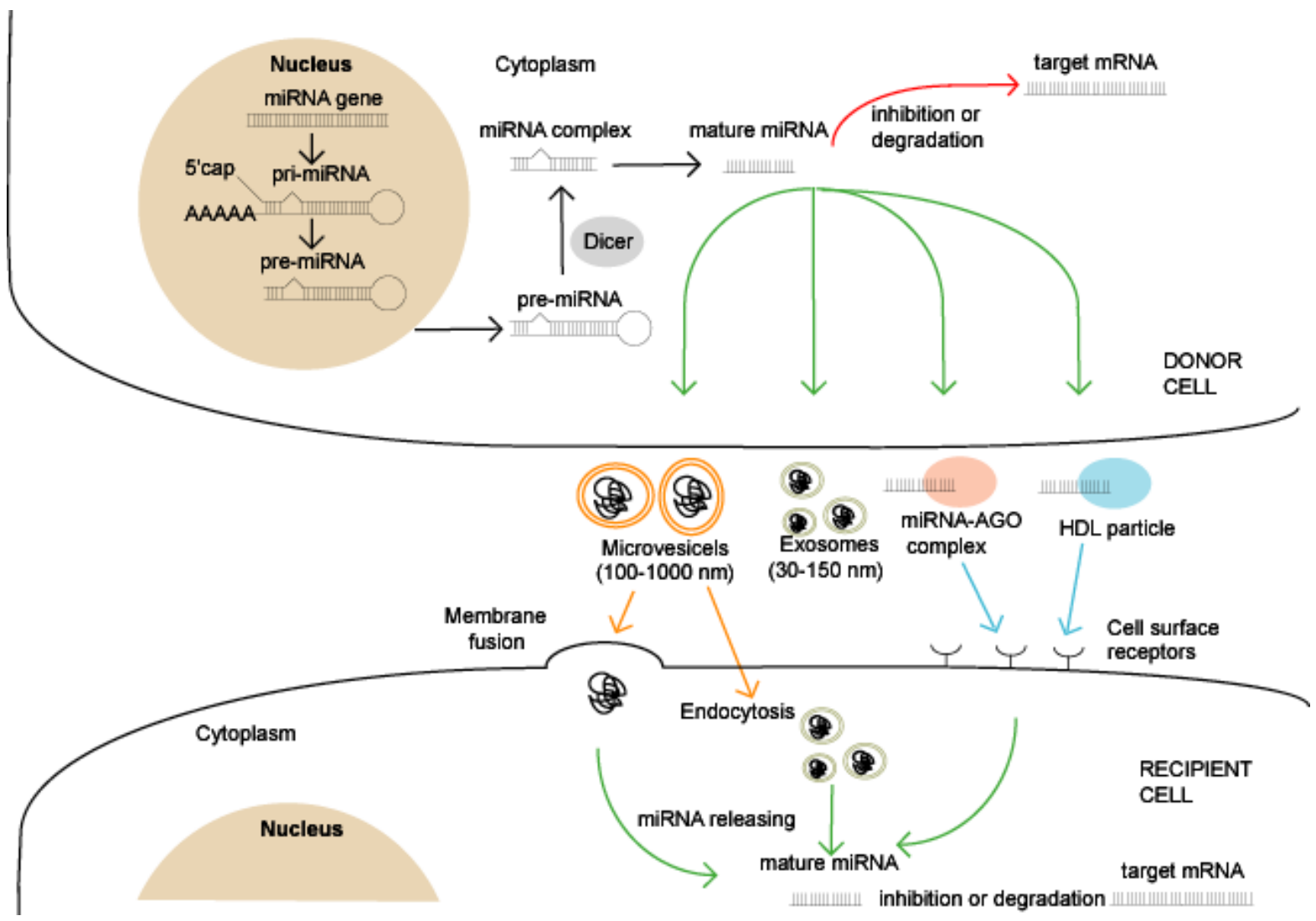

Figure 1. miRNA biogenesis, secretion and uptake 
The miRNA genes are transcribed in the nucleus to produce primary miRNA (pri-miRNA). Subsequently, pri-miRNA is further converted to the precursor miRNA (pre-miRNA) and transported to the cytoplasm. In the cytoplasm, an enzyme Dicer cleaves pre-miRNA into miRNA duplex, which eventually releases mature miRNA. In turn, mature miRNA mainly targets cytoplasmic mRNA, resulting in the translation inhibition or mRNA degradation. Additionally, miRNA can also be secreted into the extracellular environment, which allows it to reach distant cells.

Extracellular miRNA may be surrounded by a vesicle-associated membrane. The transporting vesicles of a normal cell include exosomes $(30-150 \mathrm{~nm})$ and microvesicles (100-1000 nm). However, the extracellular miRNA may be also non-vesicle associated, when carried by ribonucleoproteins, mostly by Argonaute 2 (Ago2), as well as transported with high density lipoproteins (HDL).

Once miRNA reaches the recipient cell, the uptake commences. Exosomes and microvesicles can be absorbed by recipient cells by endocytosis or by direct fusion with the plasma membrane. HDL-associated miRNAs and miRNA-AGO2 complexes are taken up by the recipient cells through binding to the specific receptors present in the cellular membrane.

Following the release in the recipient cells, miRNAs control protein synthesis, mainly by means of targeting mRNA, which further leads to its inhibition or degradation.

\section{2. miRNA sorting into exosomes}

Exosomes are 30 to $100 \mathrm{~nm}$-sized type of extracellular vesicles secreted by most cell types into the extracellular space and were broadly characterised in Minimal information for studies of extracellular vesicles [3]. In fact, as carriers of different biomolecules, including proteins, lipids or nucleic acids, exosomes play an essential role in physiological and pathological states [4]. They participate in cell-to-cell communication and act as mediators, modulating the activity of other cells, with exosome content being transported not only into the surrounding cells, but also to more distant tissues [1]. Moreover, they are capable of triggering a systemic response. However, the mechanisms of information exchange between cells are extensive and not fully understood.
In terms of the exosomal resident transcripts, particular attention has been given to miRNAs, due to their high conservation across species, involvement in gene expression regulation and the role of signalling molecules in metastatic tumour cell growth. Unfortunately, the molecular mechanisms controlling the specific loading of miRNAs into exosomes remain poorly understood. Both selecting and non-selecting mechanisms have been described in this context, and it is suggested that several loading mechanisms may govern exosome sorting of specific subsets of miRNAs $[5,6]$. In fact, on the basis of the current research, several pathways have been described which impact sorting of miRNAs into exosomes, i.e. 1) the neutral sphingomyelinase 2 (nSMase2) membrane protein-dependent pathway; 2) the loading of miRNAs controlled by hnRNPA2B1 SUMOylation, 3) the 3'-end of the miRNA sequence-dependent pathway; 4) the miRNA induced silencing complex (miRISC)-related pathway, where Argonaute 2 (Ago2) is reportededly involved in the sorting of such genes as let-7a, miR-100, and miR-320a; 5) other RNA-binding proteins related pathways since the conducted studies proved that specific proteins might govern miRNA sorting by means of recognising and binding to specific RNA sequences called the EXO motif [7]. Moreover, research conducted to date has demonstrated that miRNA are selectively packed into exosomes by a mechanism dependent on RNA binding proteins (RBPs) [7], and RBPs, in turn, form complexes with RNAs and transport them into exosomes during biosynthesis [8].

There is evidence that short sequence motifs (EXOmotifs) are overrepresented in miRNAs and connected with the process of sorting the miRNAs into exosomes, e.g. hnRNPA2B1 complex binds and loads specifically about 30 exosomal miRNAs through the recognition of GGAG motif (e.g. identified in the T cells) [9]. Furthermore, it has been reported that some miRNAs proved to promote cancer metastasis and are selectively sorted into exosomes, such as miR-122 containing complex, bipartite motifs (UGGA at the $5^{\prime}$ end, UUU at the $3^{\prime}$ end) [6]. Additionally, identifying the GCAG motif in the miR-1246 sequences further supports the concept that RNA sequence motifs are a crucial factor responsible for the selective cellular miRNA sorting into exosomes [10]. 


\section{Close and distant miRNA peregrinations outside the cell}

Extracellular RNA is found in biological fluids in large quantities and is detected in saliva, blood, cerebrospinal fluid, breast milk, semen, and urine [11]. RNA present in the extracellular fluids originates from endogenous and exogenous sources. miRNA can be expelled from cells due to cell death, in the course of apoptosis or necrosis [12]. Moreover, RNA may also be released as a paracrine signal for communication with other cells. The exogenous extracellular RNA might be derived from another organism (foreign RNA) and can be exchanged between different kingdoms in the horizontal transfer process. In fact, horizontal transfer has been observed between RNA viruses and eukaryotes, plants and viruses, plants and mammals or other animals $[13,14]$.

In general, the concentration of miRNA in the extracellular space is much smaller than in cells, due to RNA-degrading enzymes in biofluids [15]. Blood cells constitute a significant contributor to the circulating miRNA [16]. However, extracellular miRNA profiling is affected by gender, age, metabolism, diet, physical exercise and general health condition. miRNAs are transported from cell-to-cell in membrane-derived vesicles, highdensity lipoprotein particles (HDLs), apoptotic bodies and a short distance through tunnelling nanotubes ( $\mathrm{TnT}$ ) [17]. In addition, miRNA is protected in the extracellular space from ribonucleases (RNases) and other degrading factors by being transported with proteins. 500 known transporting proteins may have a specific affinity, forming stable ribonucleoprotein complexes with RNA and it is assumed that more than $90 \%$ of circulating miRNAs in plasma are associated with proteins [18]. The most abundant form of extracellular RNA (ex-miRNA) in the blood is bound with Ago2, suggesting that the RNA protection mechanism may be the most effective. Another ribonucleoprotein involved in the transport, stabilisation and protection of miRNA is nucleophosmin 1 (NPM1). Primarily, NMP1 has been known as a nucleolus protein, participating in ribosomal RNA processing. According to the studies by Kai Wang et al., NPM1 participates in the exportation and ex-miRNA protection [19], but it may also be transported with high-density lipoproteins [20].
miRNA can be transported between cells through direct connections without entering the extracellular space. One of the direct connections is referred to as TnT and connect cells and communicate by electrical signals, exchange proteins, nucleic acids and organelles [21]. Another way for miRNA to be transported between cells is a gap junction, which directly connects two cells by a channel consisting of connexins. Although gap junctions are used predominantly to transport small molecules, such as water or ions, they also transport RNA, proteins and other molecules [22].

In healthy individuals, the amount of vesicleassociated RNA is minimal, since most extracellular RNA is protein-associated; conversely, it increases in pathological states. Interestingly, breast cancer patients present significantly increased levels of vesicle-associated exosomal RNA, which may indicate the degree of disease severity [23]. Thus, the amount of extracellular RNA, its type and its method of transport are affected by various factors, and, due to that, they differ in certain organisms and tissues, which should be taken into consideration in its analysis.

Approximately $1-3 \times 10^{12}$ exosomes could be derived from $1 \mathrm{ml}$ of the human serum, and these exosomes contain $0.5-2.5 \mathrm{ng}$ of RNA [24], and miRNAs levels for various cell types are estimated in the range of tens to 120,000 copies per cell [25]. The variety of miRNAs present in extracellular vesicles could become a diagnostic marker for breast cancer. EVs released from hepatocytes could indicate liver insufficiency, whereas exosomes from the placenta might become a diagnostic biomarker of the foetal disease [26]. According to the studies, specific miRNA is only associated with EVs, such as let-7a [27].

HDL had become the focus of new studies which suggest that HDL is a miRNA transporter and a protector from RNases in the circulatory system. Nevertheless, the process of releasing miRNA associated with HDL and the role of HDL in gene modification remains unknown. An investigation of miRNA-HDL complexes by Wagner et al. presents that miR-223, miR-92a, and miR-126 are more likely to be associated with HDL. However, the highest ratio of miRNA-HDLA complex to the entire circulating miRNA was below $10 \%$, indicating that HDL cannot be a significant transporter of miRNA. The same study referred to a specific miRNA associated with the low-density lipopro- 
tein (LDL), miR-155, which resulted in atherosclerosis in more vulnerable organisms [28].

It has been suggested that circulating miRNA-protein complexes are able to participate in paracrine functions, and that miRNA encapsulated in exosomes might play a role in intercellular communication [18]. Furthermore, investigation of miRNA concentration kinetics in the blood is required, particularly for miRNA associated with exosomes. These particles contributing to intercellular communication could be molecular capsules involved in drug delivery to cells [18].

\section{Transfer from the circulation into the cells}

\subsection{RNA entrance into target cells and \\ the impact on gene expression}

Several mechanisms allow for the entrance of RNA into target cells, thus affecting gene expression. One mechanism of RNA entering into cells is internalisation mediated via exosomes. In fact, they play a role in the communication of neoplastic cells and deliver mRNAs and miRNAs into target cells [29]. Zhang et al. demonstrated that the miR-150 packaged into exosomes entered Human Microvascular Endothelial Cells (HMEC-1 cells) [30]. The binding of exosomes onto target cells can be mediated through receptors present on the cell surface, with MHC I, MHC II, tetraspanins, and transferrin being the receptors involved in exosome transportation [31]. The exosome membrane surface, especially proteins, could be investigated as potential mediators of exosome docking on the target cell membrane [29]. Subsequently fusion of exosomes with the cell membrane occurs, which could be limited by the low $\mathrm{pH}$ of the tumour microenvironment, since the optimal $\mathrm{pH}$ of the membrane internalisation is about 5.0. Therefore, this $\mathrm{pH}$ is optimal to achieve the highest fluidity of membranes and fusion potential [32]. Furthermore, endocytosis, including phagocytosis, is also an established internalisation mechanism [31]. Heparan sulfate proteoglycans (HSPGs) were described as mediators in exosome internalisation with destination cells, in particular in exosomes released by cancer cells. Moreover, it has been demonstrated that HSPGs play a significant role in the uptake of exosomes. This phenomenon could be important for the development of exosomes delivering RNA therapeutics into cancer cells.

miRNAs, present in the circulatory system and extracellular fluid compartments, can affect cells located far away from the donor cell, and as a result, they can alter cell gene expression [33]. The miRNA activity could be referred to as "hormone-like", since this molecule requires interaction with a receptor situated within the cell, or on the cell membrane. The possible mechanism of hormone-like activity of miRNA involves a protein receptor for miRNA (miRceptor) and a potential miRNA-protein interaction which was first observed in 2010 [34]. Direct miRNA-protein interplay occurs in chronic myelogenous leukaemia cells between miR-328 and the heterogeneous ribonuclear protein E2 (hnRNP E2). hnRNP E2 inhibits CCAAT/enhancer-binding protein a (CEBP-a), leading to an inhibition in granulocytic differentiation. The best-known mechanism of controlling gene expression by miRNA is the repression of translation. It is performed by a pairing of six bases in $5^{\prime}$-end located in miRNA seed region with the 3'UTR sequence on the target mRNAs and, as a result, inhibiting the translation or, more radically, initiating the degradation of mRNA [2].

The aforementioned mechanisms of gene regulation are also mediated by incoming miRNA in the target cells. By means of the transport through EVs, the expression of miR-409 in stromal fibroblasts can affect other cells and promote tumorigenesis via repression of tumour suppressors, such as RAS suppressor 1 (RSU1), as it was demonstrated in prostate fibroblasts [35]. On the other hand, miRNA, such as miR-135a, is also involved in tumour growth repression, where it suppresses the invasiveness of prostate cancer cells by impacting ROCK1 and ROCK2 [36].

\subsection{The role of imported miRNAs in the target cells - preparation for cancer progression} In order to better understand the role of miRNA on cells, one should look at the immediate environment of the tumour. The tumour microenvironment (TME) is defined as the area enclosing the tumour which contains cancer as well as stromal cells, fibroblast, and immune cells. The TME is rich in signalling molecules, blood vessels, and the extracellular matrix (ECM) [37]. The TME creates optimal conditions for tumour development, 
growth and metastasis, supplies nutrients and provides a physical scaffold for cells [37]. miRNAs, secreted by the tumour cells, can impact other cells in the TME on several levels. Finally, similarly to hormones, miRNAs can be transported through the bloodstream to modify a healthy microenvironment, making it suitable for metastasis. Recent studies have indicated that miRNAs play a significant role in metastasis [38]. In this paper we report the representative examples of how miRNA can modify a local and distant cell microenvironment, so as to promote tumour growth and enhance metastasis formation.

\subsubsection{Modulation of the vascular permeability and angiogenesis}

The ability of cancer to form metastasis and invade distant organs requires miRNAs to facilitate this process by promoting vascular permeability and angiogenesis. miR-105 was reported to destroy the vascular endothelial barrier and to promote metastasis by targeting the tight junction protein Z0-1. As a result of the destruction of tight junctions, the integrity of the barrier is compromised, increasing vascular permeability and leading to metastatic progression [39]. Other studies have demonstrated that over-expression of miR-939 targeting vascular endothelial cadherin (VE-cadherin) results in an increased permeability of human umbilical vein endothelial cells (HUVEC) [40]. Finally, miRNA is involved in forming new vessels, and although miRNA alone is not sufficient to induce metastasis, they greatly contribute to the process.

\subsubsection{Immune modulation}

Tumour cells secrete extracellular vesicles transporting miRNA, which are taken up by surrounding cells in the tumour microenvironment and by cells in distant organs [41]. It is worth noting that tumour extracellular vesicles can promote cancer angiogenesis, invasion and metastasis. Immune cells of myeloid and lymphoid origin are part of the tumour microenvironment, with myeloid cells being widely present in tissues. In fact, they comprise most immune cells and play an essential role in immune reactions and tissue remodelling. Different subsets of mature myeloid cells, such as monocytes, macrophages, dendritic cells and granulocytes take up EV and acquire a pro-tumorigenic phenotype. In the course of neoplasm formation, the differentiation of myeloid cells and their functions are impaired, resulting in tumour promotion. A high capacity of myeloid cells to EV uptake from circulation enables the formation of pre-metastatic niches [42]. The exposure of myeloid cells to tumour EV could inhibit the antitumour function of $T$ cells and natural killer cells and promote tumour progression. Hence, immune cells establish a pro-inflammatory environment, which stimulates tumour growth and partially suppresses the anti-cancer immune response [43]. Moreover, lung cancer cells secrete miR-21 and miR-29a, which bind and activate toll-like receptors (TLR) 7 and 8, inducing the secretion of pro-inflammatory cytokines, such as IL-6 and TNF- $a$ which facilitate tumour growth and metastasis formation [44]. Although immense data indicate the involvement of miRNA in immunomodulation of tumorigenesis, the participation of circulating miRNA in the process has not been well described. Nevertheless, it has been reported that miR-195 and miR-497 inhibit CD274 expression, affecting the immune response. Other studies have shown that overexpression of miR-203 in pancreatic adenocarcinoma leads to downregulation of TLR4 on pancreatic dendritic cells, inducing immune tolerance [45]. Similarly, miR-212-3p inhibits regulatory factor $\mathrm{X}$-associated protein, i.e. an important transcription factor for major histocompatibility complex (MHC) II, which results in a decreased MHC II expression and immune tolerance of dendritic cells in pancreatic carcinoma [46].

\subsubsection{Drug resistance}

miRNAs contribute to the drug resistance of tumour cells by means of targeting genes related to cell proliferation, cell cycle, and apoptosis. Moreover, drug-resistant tumour cells can spread resistance to other non-resistant cells, which leads to treatment failure [47]. In the MCF-7 breast cancer cell line, the altered expression of miRNA-21 affects the susceptibility to doxorubicin used to treat breast cancer. Additionally, other studies have demonstrated that upregulated expression of miR-106a contributes to cisplatin resistance in non-small cell lung carcinoma [48]. Similarly, miR-15b increases the resistance of lung adenocarcinoma cells to cisplatin by suppressing phosphatidylethanolamine-binding protein 4 [49]. The miR-23a overexpression in colon 
cancer cells is reported to lead to resistance to 5 -fluorouracil, with the mechanism of miR-23ainduced resistance decreasing the level of apoptosis-activating factor- 1 in the colorectal cancer cells [50]. Furthermore, exosomal short-distance transfer of miRNAs may also lead to the development of chemoresistance. Tumour-associated macrophages receive miR-1246 abundant exosomes derived from paclitaxel-resistant epithelial ovarian carcinoma cells, and miR-1246 further promotes paclitaxel resistance. In contrast, epithelial ovarian carcinoma cells receive miR21 abundant exosomes from cancer-associated adipocytes and fibroblasts, resulting in paclitaxel resistance. Moreover, in hypoxic conditions, miR223 enriched tumour-associated macrophagederived exosomes promote cisplatin resistance in epithelial ovarian carcinoma cells via the PTENPI3K/AKT pathway [51]. Interestingly, miRNAs may also be associated with melanoma resistant to treatment with immune checkpoint inhibitors (ICls) [52].

Recent studies have suggested that cancerderived exo-miRs are released in a different pattern, which is assumed to display multi-drug resistance through the mechanisms described above [53]. As described in a recent review, secreted exo-miRs prepare the cell microenvironment for cancer evolution, therefore, chemotherapy resistance affects all types of tumour cells [53]. On the other hand, microenvironment cells (such as macrophages and fibroblasts) are considered to transmit multi-drug resistance to sensitive neighbouring cells. In all of the abovementioned scenarios, exo-miRs play a major role in cancer drug resistance.

\section{Diagnostic significance of circulating miRNAs.}

Shortly after the discovery of circulating miR$\mathrm{NA}$, these molecules have been observed to be potential diagnostic and prognostic biomarkers in cancer. There are at least three main objectives in the use of circulating miRNA as cancer markers: early diagnosis markers (predictive biomarkers), molecular classifiers, as well as relapse monitoring markers (prognostic biomarkers) [54]. The predictive biomarkers could be helpful in the regular monitoring of a high-risk group of patients. There are numerous examples of studies aiming to elaborate on predictive biomarkers [55]. For instance, the MiR-17-92 is one of the oncogenic miRNA clusters involved in colorectal carcinogenesis, and levels of MiR-17, miR-18a, miR19a, miR-20a, miR-19b and miR-92a - members of this cluster increase in colorectal cancer plasma samples [55]. Hence, it is of importance, as early detection of colorectal cancer, markedly improves the prognosis. Other studies have also associated the expression of miR-17 also with cervical cancer [56]. The most frequent neoplasm in women is breast cancer, which is characterised by heterogeneity and variable subtypes differing in grade and malignancy, which in consequence, necessitates a diversified therapeutic approach. In order to distinguish breast cancer types, reliable molecular classifiers markers have been investigated [57]. As a result, it was demonstrated that the miRNAs expression profile could distinguish the triple-negative breast cancer from other molecular breast cancer subtypes [58, 59]. The relapse prognostic biomarkers could be a form of post-surgery or a radiotherapy monitoring marker. In post-surgical plasma samples, the tests showed good performance with regard to monitoring disease relapse.

On the basis of screening cohorts comprising lung cancer patients, circulating miRNA pre-test were designed by selecting miRNA biomarkers - a non-commercial experimental miRNA signature classifier test based on a microfluidics card containing the 24 miRNAs. Although the miR-Test uses 13-miRNA types, such experimental tests resulted in a fourfold to fivefold reductions in the low-dose computed tomography false-positive rate $[60,61]$. ThyraMIR classifies the gene expressions of ten microRNAs, and it allows physicians to identify thyroid cancer with a single test. According to the supplier, ThyraMIR and ThyGenX present a specificity of $85 \%$ and sensitivity of $89 \%$. ThyraMIR uses the expression levels of 10 microRNAs, whereas ThyGenX aims at mutations or genetic alterations associated with thyroid cancer. In combination, the two tests are used to produce a positive or negative result from the routine fine-needle aspiration procedures [62].

The significance of circulating miRNA in diagnostic tests has been developing dynamically in the breast cancer area. Researchers discovered that the concentration of miRNA-29b-2 and miR- 
NA-155 was higher in blood serum in samples from patients who suffer from breast cancer compared to non-breast cancer patients. Therefore, these findings could suggest that an increase in the concentration of certain molecules of miRNA in the blood serum may result from oncogene activation. Conversely, the amount of other types of miRNA decreases in the aftermath of a suppressor gene turning off. Taking the abovementioned facts into account, diagnostic kits should be developed which would reliably exclude or confirm the diagnosis of breast cancer or enable the development of cancer screening with miRNA.

In the past, research regarding the efficacy of miRNA panels in the detection of colorectal cancer was conducted. Researchers investigated examined a panel of 8 miRNAs, which distinguish patients with polyps from patients without them (miRNA-532-3p, miRNA-331, miRNA-195, miRNA17, miRNA-142-3p, miRNA-15b, miRNA-532, and miRNA-652) and a panel of 3 miRNAs, which distinguish patients with stage IV colorectal cancer from patients without colorectal cancer (miRNA431, miRNA-15b, and miRNA-139-3p). The differentiation between patients with and without cancer by the panels demonstrated high accuracy. The sensitivity of the test, both in the group of patients with colorectal adenomas and the control group, amounted to $88 \%$, while the specificity reached $64 \%$. In addition, the comparison between stage IV colorectal cancer patients and the control group was $93 \%$ and $74 \%$, respectively [63].

Several similar studies have shown that breast cancer [56], prostate [64], colorectal [65], gastric and others [65] are all candidates for 'potential' miRNA biomarkers This, in turn, raises the question as to why the considerable data on the potential biomarkers have not been efficiently transformed into clinically useful diagnostic tests [66]. The information on the website https://clinicaltrials.gov/ concerning recent ongoing clinical trials involving miRNA biomarkers, comprises one completed study 'Circulating miRNAs as Biomarkers of Hormone Sensitivity in Breast Cancer in phase IV, no studies in phase III, one study in phase II and one study in phase I. In order to be able to make a correct clinical diagnosis of a patient's sample, the most critical evaluation criteria for biomarkers are high sensitivity and specificity [67]. miRNA and expression markers are usually determined on a large cohort, and as such display some bias and rarely reach sufficient specificity and reproducibility in a particular patient sample. This is problematic for miRNAs, which are deregulated due to primary genetic or epigenetic alterations [68]. Furthermore, a number of uncontrollable factors and stochastic fluctuations hinder the estimation of miRNA level in circulation. Recent works suggest genetically programmed-in fluctuations within miRNA pools, possibly driving the formation of adaptive phenotypes [69].

This poses the question, whether there are any advantages to using miRNA markers miRNA is relatively stable in ex vivo blood samples and over 200 types detectable in blood serum by the most sensitive method. Therefore, this broad spectrum of molecules enables the recruitment of several reliable sequences to increase the specificity of a potential test [67]. Circulating miRNAs for diagnostic tests are collected as a liquid biopsy from plasma or serum [70]; nevertheless, easily accessible plasma and serum vary, and so different results are obtained [66]. Serum is considered a better option, since it is less likely to contain products of haemolysis. A decreased circulating miRNA level compared with the cytoplasmic miRNA concentration requires the use of particular methods to detect it [71]. The two most common methods to detect miRNA in serum are microarrays and quantitative reverse transcriptase realtime PCR (RT-qPCR) [72].

The disadvantages of miRNA markers might seemingly outweigh the advantages. In fact, miRNAs indicates altered expression patterns in the same type of cancer assayed by different studies, and miRNA levels are dependent on age, gender, ethnicity, lifestyle, pre-treatment, history of diseases. Additionally, in terms of detection results, they can be affected by the measurement principle, the method used and the instrument and also haemolysis should be strictly controlled in plasma samples [67]. In a relative quantification of circulating miRNA, the lack of a normaliser is the most significant obstacle. An additional challenge is the fact that miRNA is predominantly secreted by healthy cells; hence, a multi-parameter assay instead of a single marker has been proposed to allow miRNA biomarker testing. However, it is has recently been suggested that in order to develop a specific test the absolute level of miRNA should be considered as more reliable [73]. 


\section{Application of miRNA as drugs and vaccines}

miRNA, as an essential tumour suppressing factor, could be used to inhibit oncogenesis. Several anti-micro-RNA therapies have already been described by Miroshnichenko et al. [74]. Here we present several examples of promising drugs based on RNA oligonucleotides which have already been in clinical trials.

The gene encoding miR-34 is regulated by $\mathrm{p} 53$ and has been observed to be decreased in several types of cancer, including prostate cancer, pancreas cancer, breast cancer and many others. Nanoparticles containing miR-34 inhibit the development of a tumour, metastasis and stimulate apoptosis. MRX34 is a form of nanoparticles containing RNA mimic tested in the first phase of the study where the drug consisted of 23-nucleotides closed in a liposomal nanoparticle [75]. MYC, MET, BCL2, and WNT $1 / 3$ are examples of inhibited oncogenes by MRX34 (93). A clinical trial has shown plenty of side effects occurring as a result of miR-34 therapy including immune responses, which probably resulted from suppressed immune-related genes by miR-34 [75]. Thus, MRX34 did not move to the second phase of trials due to high toxicity [76].

Imetelstat (GRN163L) is an oligonucleotide, a second phase trial drug, which acts as RNA's telomerase inhibitor. GRN163L exhibits antiproliferative and cytotoxic effects. The treatment of haematological cancers and solid tumours affects the delay in megakaryopoiesis [77]. The research presents possible action on reducing malicious hematopoietic stem cells and hematopoietic progenitor cells in myelofibrosis. Nevertheless, thrombocytopenia constitutes the toxicity factor limiting the drug's dosage [78].

An exciting novelty among miRNA's drugs is RGLS5579. The oligonucleotide inhibits miR-10b, whereas the overexpression of miR-10b occurs in colorectal and breast cancer, where it promotes metastasis [79]. The drug could be administered to patients diagnosed with glioblastoma multiforme, which is the most aggressive type of cancer of the brain [76].

"TargomiR" technology is based on targeted minicells containing miRNA mimic [80]. The first drug using this novelty technique is MesomiR-1. The first phase of clinical trials was completed, as a result of which MesomiR-1 based on miR-16 was most likely to suppresses tumours on the scale of cancer types [79]. The research was conducted on patients with malignant pleural mesothelioma and non-small-cell lung carcinoma. The drug was considered safe due to benign side effects [81].

The role of miR-155 is an oncomir regulating pathways in immune cells. Cobomarsen (MRG106) is introduced as a synthetic anti-miR-155 oligonucleotide in second phase trials. The drug was administered to patients with haematological malignancies [82]. Cobomirsen decreases cellular proliferation and generates apoptosis in mycosis fungoides. MGR-106 is currently being tested for safe use and tolerability.

siRNA drugs, based on RNA interference, degrade mRNA in a long-lasting period. It is essential to deliver the drug in lipid or $\mathrm{N}$-acetylgalactosamine (GalNAc)-conjugated nanoparticles to enable transport of siRNA into hepatocytes. [83]. Gene knockdown effects of doublestranded siRNA therapeutics were used in several clinical trials. APN401, EphA2 siRNA, ALN-VSP02, CALAA-01 and DCR-MYC are examples of drugs remaining in the first phase. siG12D-LODER and TKM-080301 were classified for the second phase trials [84].

The delivery of EVs from the tumour into the destination cells could be facilitated by means of polyethyleneimine (PEI). PEI is the synthetic polymer of different molecular weights generated by aziridine monomers. The modification of EVs with $\mathrm{PEI} / \mathrm{siRNA}$ complexes significantly increases RNA molecules' uptake carried by exosomes. This uptake may improve the uptake of exosomemediated drug transfer against cancer, although it was mainly investigated in vitro [85]. Several RNAbased vaccines contain genes situated in a bacterial plasmid. The majority of vaccines do not have preventive activity, although they are based on the stimulation of cell responses. Dendritic cells are used to deliver mRNA to the cells. Dendritic cells with antigens related to melanoma combined with monoclonal antibodies against CTL antigen four results in a decrease in tumour size. Another solution of mRNA application includes a direct injection into the secondary lymphoid tissue, intranasal, intratumoral, intradermal, systemic administration using lipid-based carriers [86]. The table presenting clinical trials with mRNA vaccines has been published by Pardi et al.[86]. 


\section{Conclusions}

It is difficult to deny the effect of miRNAs secreted by cancer cells on other body cells. However, despite extensive research, there are still issues with regard to the understanding the selection of miRNAs packed into EVs. The mechanisms of the selective uptake of EVs by cells from extracellular space remains obscure. Nevertheless, the phenomenon of gene expression regulation by incoming small amounts of miRNA in recipient cells requires further research. miRNA has excellent potential for future use as a biomarker, and more efforts should be made to reveal its mechanisms in order to develop new diagnostic and treatment methods.

\section{Acknowledgements}

\section{Conflict of interest statement}

The authors declare no conflict of interest.

\section{Funding sources}

This paper was co-funded by the National Science Centre - NCN (Poland), as part of the programme MINIATURA 4, grant number: 2020/04/X/ST6/00759.

\section{References}

1. O'Brien K, Breyne K, Ughetto S, Laurent LC, Breakefield XO. RNA delivery by extracellular vesicles in mammalian cells and its applications. Nat Rev Mol Cell Biol. 2020 21(10): 585-606. PMID: 32457507.

2. Bartel DP. Metazoan MicroRNAs. Cell. 2018 173(1): 20-51. PMID: 29570994.

3. Thery C, Witwer KW, Aikawa E, Alcaraz MJ, Anderson JD, Andriantsitohaina R, Antoniou A, Arab T, Archer F, Atkin-Smith GK, Ayre DC, Bach JM, Bachurski D, Baharvand H, Balaj L, Baldacchino S, Bauer NN, Baxter AA, Bebawy M, Beckham C, Bedina Zavec A, Benmoussa A, Berardi AC, Bergese P, Bielska E, Blenkiron C, Bobis-Wozowicz S, Boilard E, Boireau W, Bongiovanni $A$, BorrĂ s FE, Bosch S, Boulanger CM, Breakefield X, Breglio AM, Brennan M, Brigstock DR, Brisson A, Broekman ML, Bromberg JF, Bryl-GĂłrecka $\mathrm{P}$, Buch S, Buck AH, Burger D, Busatto $S$, Buschmann D, Bussolati B, BuzĂ`s El, Byrd JB, Camussi G, Carter DR, Caruso S, Chamley LW, Chang YT, Chen C, Chen S, Cheng L, Chin AR, Clayton A, Clerici SP, Cocks A, Cocucci E, Coffey RJ, Cordeiro-da-Silva A, Couch Y, Coumans FA, Coyle B, Crescitelli R, Criado MF, D'Souza-Schorey C, Das S, Datta Chaudhuri A, de Candia P, De Santana EF, De Wever O, Del Portillo HA Demaret T, Deville S, Devitt A, Dhondt B, Di Vizio D, Dieterich LC, Dolo V, Dominguez Rubio AP, Dominici M, Dourado MR, Driedonks TA, Duarte FV, Duncan HM, Eichenberger RM, EkstrĂ $\mathrm{m}$ K, El Andaloussi S, Elie-Caille C, ErdbrăL'gger U, FalcĂłn-PĂ@rez JM,
Fatima F, Fish JE, Flores-Bellver M, FĂ IrsĂ Inits A, Frelet-Barrand A, Fricke F, Fuhrmann G, Gabrielsson S, GǍmez-Valero A, Gardiner C, GĂartner K, Gaudin R, Gho YS, Giebel B, Gilbert C, Gimona M, Giusti I, Goberdhan DC, GĂ rgens A, Gorski SM, Greening DW, Gross JC, Gualerzi A, Gupta GN, Gustafson D, Handberg A, Haraszti RA, Harrison P, Hegyesi $H$, Hendrix A, Hill AF, Hochberg FH, Hoffmann KF, Holder B, Holthofer $\mathrm{H}$, Hosseinkhani B, Hu G, Huang Y, Huber V, Hunt S, Ibrahim AG, Ikezu T, Inal JM, Isin M, Ivanova A, Jackson HK, Jacobsen S, Jay SM, Jayachandran $M$, Jenster $G$, Jiang $L$, Johnson SM, Jones JC, Jong A, Jovanovic-Talisman T, Jung S, Kalluri R, Kano SI, Kaur S, Kawamura Y, Keller ET, Khamari D, Khomyakova E, Khvorova A, Kierulf P, Kim KP, Kislinger $T$, Klingeborn $M$, Klinke DJ, 2nd, Kornek M, KosanoviÄł MM, KovǍcs Ă F, KrĂamer-Albers EM, Krasemann S, Krause M, Kurochkin IV, Kusuma GD, Kuypers $S$, Laitinen S, Langevin SM, Languino LR, Lannigan J, LĂasser C, Laurent LC, Lavieu G, LǍzaroIb $\breve{A} \breve{A} \pm$ ez E, Le Lay S, Lee MS, Lee YXF, Lemos DS, Lenassi M, Leszczynska A, Li IT, Liao K, Libregts SF, Ligeti E, Lim R, Lim SK, LinÄ“ A, Linnemannstă ${ }^{\prime} n s$ K, Llorente A, Lombard CA, Lorenowicz MJ, LĂ 9 rincz A $\mathrm{M}$, LĂ tvall J, Lovett J, Lowry MC, Loyer X, Lu Q, Lukomska B, Lunavat TR, Maas SL, Malhi H, Marcilla A, Mariani J, Mariscal J, Martens-Uzunova ES, Martin-Jaular L, Martinez MC, Martins VR, Mathieu M, Mathivanan S, Maugeri M, McGinnis LK, McVey MJ, Meckes DG, Jr., Meehan KL, Mertens I, Minciacchi VR, MĂવller A, MĂ,ller JĂ,rgensen M, Morales-Kastresana A, Morhayim J, Mullier F, Muraca M, Musante L, Mussack V, Muth DC, Myburgh KH, Najrana T, Nawaz M, Nazarenko I, Nejsum P, Neri C, Neri T, Nieuwland R, Nimrichter L, Nolan JP, Nolte-'t Hoen EN, Noren Hooten N, O'Driscoll L, O'Grady T, O'Loghlen A, Ochiya T, Olivier M, Ortiz A, Ortiz LA, Osteikoetxea X, A stergaard O, Ostrowski M, Park J, Pegtel DM, Peinado H, Perut F, Pfaffl MW, Phinney DG, Pieters BC, Pink RC, Pisetsky DS, Pogge von Strandmann E, Polakovicova I, Poon IK, Powell BH, Prada I, Pulliam L, Quesenberry P, Radeghieri A, Raffai RL, Raimondo S, Rak J, Ramirez MI, Raposo G, Rayyan MS, RegevRudzki N, Ricklefs FL, Robbins PD, Roberts DD, Rodrigues SC, Rohde E, Rome S, Rouschop KM, Rughetti A, Russell AE, Sa Ǎ P, Sahoo S, Salas-Huenuleo E, SĂ nchez C, Saugstad JA, Saul MJ, Schiffelers RM, Schneider R, SchĂ yen TH, Scott A, Shahaj E, Sharma S, Shatnyeva O, Shekari F, Shelke GV, Shetty AK, Shiba K, Siljander PR, Silva AM, Skowronek A, Snyder OL, 2nd, Soares RP, SĂłdar BW, Soekmadji C, Sotillo J, Stahl PD, Stoorvogel W, Stott SL, Strasser EF, Swift S, Tahara H, Tewari M, Timms K, Tiwari S, Tixeira R, Tkach M, Toh WS, Tomasini R, Torrecilhas AC, Tosar JP, Toxavidis V, Urbanelli L, Vader $P$, van Balkom BW, van der Grein SG, Van Deun J, van Herwijnen MJ, Van Keuren-Jensen K, van Niel G, van Royen $M E$, van Wijnen AJ, Vasconcelos MH, Vechetti IJ, Jr., Veit TD, Vella LJ, Velot Ă, Verweij FJ, Vestad B, ViĂ \pm as $\mathrm{JL}$, Visnovitz T, Vukman KV, Wahlgren J, Watson DC, Wauben MH, Weaver A, Webber JP, Weber V, Wehman AM, Weiss DJ, Welsh JA, Wendt S, Wheelock AM, 
Wiener Z, Witte L, Wolfram J, Xagorari A, Xander P, Xu J, Yan X, YĂ $\breve{A} \pm$ ez-MĂł M, Yin H, Yuana Y, Zappulli V, Zarubova J, ĹÄ-kas V, Zhang JY, Zhao Z, Zheng L, Zheutlin AR, Zickler AM, Zimmermann P, Zivkovic AM, Zocco D, Zuba-Surma EK. Minimal information for studies of extracellular vesicles 2018 (MISEV2018): a position statement of the International Society for Extracellular Vesicles and update of the MISEV2014 guidelines. J Extracell Vesicles. 2018 7(1): 1535750. PMID: 30637094.

4. Baj-Krzyworzeka M, Szatanek R, Weglarczyk K, Baran J, Urbanowicz B, BraĹ, ski P, Ratajczak MZ, Zembala $M$. Tumour-derived microvesicles carry several surface determinants and mRNA of tumour cells and transfer some of these determinants to monocytes. Cancer Immunol Immunother. 2006 55(7): 808-18. PMID: 16283305

5. Santangelo L, Giurato G, Cicchini C, Montaldo C, Mancone C, Tarallo R, Battistelli C, Alonzi T, Weisz A, Tripodi M. The RNA-Binding Protein SYNCRIP Is a Component of the Hepatocyte Exosomal Machinery Controlling MicroRNA Sorting. Cell Rep. 2016 17(3): 799-808. PMID: 27732855.

6. Temoche-Diaz MM, Shurtleff MJ, Nottingham RM, Yao J, Fadadu RP, Lambowitz AM, Schekman R. Distinct mechanisms of microRNA sorting into cancer cell-derived extracellular vesicle subtypes. Elife. 2019 8. PMID: 31436530.

7. Wei $H$, Chen $Q$, Lin $L$, Sha $C$, Li T, Liu $Y$, Yin $X, X u Y$, Chen L, Gao W, Li Y, Zhu X. Regulation of exosome production and cargo sorting. Int J Biol Sci. 2021 17(1): 163-177. PMID: 33390841.

8. Perez-Boza J, Lion M, Struman I. Exploring the RNA landscape of endothelial exosomes. Rna. 2018 24(3): 423-435. PMID: 29282313.

9. Villarroya-Beltri C, Gutierrez-Vazquez C, SanchezCabo F, Perez-Hernandez D, Vazquez J, Martin-Cofreces N, Martinez-Herrera DJ, Pascual-Montano A, Mittelbrunn M, Sanchez-Madrid F. Sumoylated hnRNPA2B1 controls the sorting of miRNAs into exosomes through binding to specific motifs. Nat Commun. 2013 4: 2980. PMID: 24356509.

10. Xu YF, Hannafon BN, Khatri U, Gin A, Ding WQ. The origin of exosomal miR-1246 in human cancer cells. RNA Biol. 2019 16(6): 770-784. PMID: 30806147.

11. Boon RA, Vickers KC. Intercellular transport of microRNAs. Arterioscler Thromb Vasc Biol. 2013 33(2): 186-92. PMID: 23325475.

12. Rayner KJ, Hennessy EJ. Extracellular communication via microRNA: lipid particles have a new message. J Lipid Res. 2013 54(5): 1174-81. PMID: 23505318.

13. Liu H, Fu Y, Jiang D, Li G, Xie J, Cheng J, Peng Y, Ghabrial SA, Yi X. Widespread horizontal gene transfer from double-stranded RNA viruses to eukaryotic nuclear genomes. J Virol. 2010 84(22): 11876-87. PMID: 20810725.

14. Han L, Luan YS. Horizontal Transfer of Small RNAs to and from Plants. Front Plant Sci. 2015 6: 1113. PMID: 26697056.

15. Max KEA, Bertram K, Akat KM, Bogardus KA, Li J, Morozov P, Ben-Dov IZ, Li X, Weiss ZR, Azizian A,
Sopeyin A, Diacovo TG, Adamidi C, Williams Z, Tuschl T. Human plasma and serum extracellular small RNA reference profiles and their clinical utility. Proc Natl Acad Sci U S A. 2018 115(23): E5334-E5343. PMID: 29777089.

16. Pritchard CC, Kroh E, Wood B, Arroyo JD, Dougherty KJ, Miyaji MM, Tait JF, Tewari M. Blood cell origin of circulating microRNAs: a cautionary note for cancer biomarker studies. Cancer Prev Res (Phila). 2012 5(3): 492-497. PMID: 22158052.

17. Han X, Wang X. Opportunities and Challenges in Tunneling Nanotubes Research: How Far from Clinical Application? Int J Mol Sci. 2021 22(5). PMID: 33669068

18. Turchinovich A, Weiz L, Langheinz A, Burwinkel B. Characterization of extracellular circulating microRNA. Nucleic Acids Res. 2011 39(16): 7223-33. PMID: 21609964.

19. Wang K, Zhang S, Weber J, Baxter D, Galas DJ. Export of microRNAs and microRNA-protective protein by mammalian cells. Nucleic Acids Res. 2010 38(20): 7248-59. PMID: 20615901.

20. Sapp RM, Shill DD, Roth SM, Hagberg JM. Circulating microRNAs in acute and chronic exercise: more than mere biomarkers. J Appl Physiol (1985). 2017 122(3): 702-717. PMID: 28035018.

21. Zhu H, Xue C, Xu X, Guo Y, Li X, Lu J, Ju S, Wang Y, Cao Z, Gu X. Rab8a/Rab11a regulate intercellular communications between neural cells via tunneling nanotubes. Cell Death Dis. 2016 7(12): e2523. PMID: 28005071

22. Beckmann A, Hainz N, Tschernig T, Meier C. Facets of Communication: Gap Junction Ultrastructure and Function in Cancer Stem Cells and Tumor Cells. Cancers (Basel). 2019 11(3). PMID: 30823688.

23. Bhat SA, Majid S, Hassan T. MicroRNAs and its emerging role as breast cancer diagnostic marker - A review. Adv Biomark Sci Technol. 2019 1: 1-8. PMID:

24. Li M, Zeringer E, Barta T, Schageman J, Cheng A, Vlassov AV. Analysis of the RNA content of the exosomes derived from blood serum and urine and its potential as biomarkers. Philos Trans R Soc Lond B Biol Sci. 2014 369(1652). PMID: 25135963.

25. Bosson AD, Zamudio JR, Sharp PA. Endogenous miRNA and target concentrations determine susceptibility to potential ceRNA competition. Mol Cell. 2014 56(3): 347-59. PMID: 25449132.

26. Janas T, Janas MM, SapoĹ ${ }^{K}$, Janas T. Mechanisms of RNA loading into exosomes. FEBS Lett. 2015 589(13): 1391-8. PMID: 25937124.

27. Gibbings DJ, Ciaudo C, Erhardt M, Voinnet O. Multivesicular bodies associate with components of miRNA effector complexes and modulate miRNA activity. Nat Cell Biol. 2009 11(9): 1143-9. PMID: 19684575.

28. Wagner J, Riwanto M, Besler C, Knau A, Fichtlscherer S, RĂ xe T, Zeiher AM, Landmesser U, Dimmeler S. Characterization of levels and cellular transfer of circulating lipoprotein-bound microRNAs. Arterioscler Thromb Vasc Biol. 2013 33(6): 1392-400. PMID: 23559634. 
29. Dragomir M, Chen B, Calin GA. Exosomal IncRNAs as new players in cell-to-cell communication. Transl Cancer Res. 2018 7(Suppl 2): S243-S252. PMID: 30148073.

30. Zhang Y, Liu D, Chen X, Li J, Li L, Bian Z, Sun F, Lu $J$, Yin Y, Cai X, Sun Q, Wang K, Ba Y, Wang Q, Wang D, Yang J, Liu P, Xu T, Yan Q, Zhang J, Zen K, Zhang CY. Secreted monocytic miR-150 enhances targeted endothelial cell migration. Mol Cell. 2010 39(1): 13344. PMID: 20603081

31. Yanez-Mo $M$, Siljander $P R$, Andreu $Z$, Zavec $A B$, Borră s FE, Buzas El, Buzas K, Casal E, Cappello F, Carvalho J, ColǍs E, Cordeiro-da Silva A, Fais S, Falcon-Perez JM, Ghobrial IM, Giebel B, Gimona M, Graner M, Gursel I, Gursel M, Heegaard NH, Hendrix A, Kierulf $\mathrm{P}$, Kokubun K, Kosanovic M, Kralj-Iglic V, KrĂamer-Albers EM, Laitinen S, LĂasser C, Lener T, Ligeti E, LinÄ“ A, Lipps G, Llorente A, LĂqtvall J, ManÄŤek-Keber M, Marcilla A, Mittelbrunn M, Nazarenko I, Nolte-'t Hoen EN, Nyman TA, O'Driscoll L, Olivan M, Oliveira C, PǍ llinger $\breve{A}$, Del Portillo HA, ReventĂłs J, Rigau M, Rohde E, Sammar M, SĂ̌nchezMadrid F, SantarĂ@m N, Schallmoser K, Ostenfeld MS, Stoorvogel W, Stukelj R, Van der Grein SG, Vasconcelos $\mathrm{MH}$, Wauben $\mathrm{MH}$, De Wever O. Biological properties of extracellular vesicles and their physiological functions. J Extracell Vesicles. 2015 4: 27066. PMID: 25979354.

32. Parolini I, Federici C, Raggi C, Lugini L, Palleschi S, De Milito A, Coscia C, lessi E, Logozzi M, Molinari A, Colone M, Tatti M, Sargiacomo M, Fais S. Microenvironmental $\mathrm{pH}$ is a key factor for exosome traffic in tumor cells. J Biol Chem. 2009 284(49): 34211-22. PMID: 19801663.

33. Pardini B, Calin GA. MicroRNAs and Long Non-Coding RNAs and Their Hormone-Like Activities in Cancer. Cancers (Basel). 2019 11(3). PMID: 30884898.

34. Fabbri M. MicroRNAs and miRceptors: a new mechanism of action for intercellular communication. Philos Trans R Soc Lond B Biol Sci. 2018 373(1737). PMID: 29158315.

35. Josson S, Gururajan M, Sung SY, Hu P, Shao C, Zhau HE, Liu C, Lichterman J, Duan P, Li Q, Rogatko A, Posadas EM, Haga CL, Chung LW. Stromal fibroblastderived miR-409 promotes epithelial-to-mesenchymal transition and prostate tumorigenesis. Oncogene. 2015 34(21): 2690-9. PMID: 25065597.

36. Kroiss A, Vincent $S$, Decaussin-Petrucci M, Meugnier E, Viallet J, Ruffion A, Chalmel F, Samarut J, Allioli N. Androgen-regulated microRNA-135a decreases prostate cancer cell migration and invasion through downregulating ROCK1 and ROCK2. Oncogene. 2015 34(22): 2846-55. PMID: 25065599.

37. Liu Q, Peng F, Chen J. The Role of Exosomal MicroRNAs in the Tumor Microenvironment of Breast Cancer. Int J Mol Sci. 2019 20(16). PMID: 31395836.

38. Puppo M, Valluru MK, ClĂ@zardin P. MicroRNAs and Their Roles in Breast Cancer Bone Metastasis. Curr Osteoporos Rep. 2021. PMID: 33830428.

39. Zhou W, Fong MY, Min Y, Somlo G, Liu L, Palomares MR, Yu Y, Chow A, O'Connor ST, Chin AR, Yen Y, Wang Y, Marcusson EG, Chu P, Wu J, Wu X, Li AX, Li Z, Gao
H, Ren X, Boldin MP, Lin PC, Wang SE. Cancer-secreted miR-105 destroys vascular endothelial barriers to promote metastasis. Cancer Cell. 2014 25(4): 501-15. PMID: 24735924.

40. Di Modica M, Regondi V, Sandri M, lorio MV, Zanetti A, Tagliabue E, Casalini P, Triulzi T. Breast cancersecreted miR-939 downregulates VE-cadherin and destroys the barrier function of endothelial monolayers. Cancer Lett. 2017 384: 94-100. PMID: 27693459.

41. Bayraktar R, Van Roosbroeck K, Calin GA. Cell-tocell communication: microRNAs as hormones. Mol Oncol. 2017 11(12): 1673-1686. PMID: 29024380.

42. Arkhypov I, Lasser S, Petrova V, Weber R, Groth C, Utikal J, Altevogt P, Umansky V. Myeloid Cell Modulation by Tumor-Derived Extracellular Vesicles. Int J Mol Sci. 2020 21(17). PMID: 32878277.

43. Omar HA, El-Serafi AT, Hersi F, Arafa EA, Zaher DM, Madkour M, Arab HH, Tolba MF. Immunomodulatory MicroRNAs in cancer: targeting immune checkpoints and the tumor microenvironment. Febs $\mathrm{J}$. 2019 286(18): 3540-3557. PMID: 31306553.

44. Fabbri M, Paone A, Calore F, Galli R, Gaudio E, Santhanam R, Lovat F, Fadda P, Mao C, Nuovo GJ, Zanesi $\mathrm{N}$, Crawford M, Ozer GH, Wernicke D, Alder H, Caligiuri MA, Nana-Sinkam P, Perrotti D, Croce CM. MicroRNAs bind to Toll-like receptors to induce prometastatic inflammatory response. Proc Natl Acad Sci U S A. 2012 109(31): E2110-6. PMID: 22753494.

45. Zhou M, Chen J, Zhou L, Chen W, Ding G, Cao L. Pancreatic cancer derived exosomes regulate the expression of TLR4 in dendritic cells via miR-203. Cell Immunol. 2014 292(1-2): 65-9. PMID: 25290620.

46. Ding G, Zhou L, Qian Y, Fu M, Chen J, Chen J, Xiang J, Wu Z, Jiang G, Cao L. Pancreatic cancer-derived exosomes transfer miRNAs to dendritic cells and inhibit RFXAP expression via miR-212-3p. Oncotarget. 2015 6(30): 29877-88. PMID: 26337469.

47. Si W, Shen J, Zheng H, Fan W. The role and mechanisms of action of microRNAs in cancer drug resistance. Clin Epigenetics. 2019 11(1): 25. PMID: 30744689.

48. Ma Y, Li X, Cheng S, Wei W, Li Y. MicroRNA-106a confers cisplatin resistance in non-small cell lung cancer A549 cells by targeting adenosine triphosphatasebinding cassette A1. Mol Med Rep. 2015 11(1): 62532. PMID: 25339370.

49. Zhao Z, Zhang L, Yao Q, Tao Z. miR-15b regulates cisplatin resistance and metastasis by targeting PEBP4 in human lung adenocarcinoma cells. Cancer Gene Ther. 2015 22(3): 108-14. PMID: 25721211.

50. Shang J, Yang F, Wang Y, Wang Y, Xue G, Mei Q, Wang $F$, Sun S. MicroRNA-23a antisense enhances 5-fluorouracil chemosensitivity through APAF-1/caspase- 9 apoptotic pathway in colorectal cancer cells. J Cell Biochem. 2014 115(4): 772-84. PMID: 24249161.

51. Yoshida K, Yokoi A, Kato T, Ochiya T, Yamamoto Y. The clinical impact of intra- and extracellular miRNAs in ovarian cancer. Cancer Sci. 2020 111(10): 3435-3444. PMID: 32750177.

52. Gajos-Michniewicz A, Czyz M. Role of miRNAs in Melanoma Metastasis. Cancers (Basel). 2020 11(3). PMID: 30866509. 
53. Mowla M, Hashemi A. Functional roles of exosomal miRNAs in multi-drug resistance in cancer chemotherapeutics. Exp Mol Pathol. 2021 118: 104592. PMID: 33296693.

54. Goossens N, Nakagawa S, Sun X, Hoshida Y. Cancer biomarker discovery and validation. Transl Cancer Res. 2015 4(3): 256-269. PMID: 26213686.

55. Marcuello M, Vymetalkova V, Neves RPL, Duran-Sanchon S, Vedeld HM, Tham E, van Dalum G, FIĂL'gen G, Garcia-Barberan V, Fijneman RJ, Castells A, Vodicka $\mathrm{P}$, Lind GE, Stoecklein NH, Heitzer E, Gironella M. Circulating biomarkers for early detection and clinical management of colorectal cancer. Mol Aspects Med. 2019 69: 107-122. PMID: 31189073.

56. Galvao-Lima LJ, Morais AHF, Valentim RAM, Barreto $E$. miRNAs as biomarkers for early cancer detection and their application in the development of new diagnostic tools. Biomed Eng Online. 2021 20(1): 21. PMID: 33593374.

57. Ellsworth RE, Blackburn HL, Shriver CD, Soon-Shiong $\mathrm{P}$, Ellsworth DL. Molecular heterogeneity in breast cancer: State of the science and implications for patient care. Semin Cell Dev Biol. 2017 64: 65-72. PMID: 27569190.

58. Kashyap D, Kaur H. Cell-free miRNAs as non-invasive biomarkers in breast cancer: Significance in early diagnosis and metastasis prediction. Life Sci. 2020 246: 117417. PMID: 32044304.

59. Sabit H, Cevik E, Tombuloglu H, Abdel-Ghany S, Tombuloglu G, Esteller M. Triple negative breast cancer in the era of miRNA. Crit Rev Oncol Hematol. 2021 157: 103196. PMID: 33307198.

60. Seijo LM, Peled N, Ajona D, Boeri M, Field JK, Sozzi G, Pio R, Zulueta JJ, Spira A, Massion PP, Mazzone PJ, Montuenga LM. Biomarkers in Lung Cancer Screening: Achievements, Promises, and Challenges. J Thorac Oncol. 2019 14(3): 343-357. PMID: 30529598.

61. Wu KL, Tsai YM, Lien CT, Kuo PL, Hung AJ. The Roles of MicroRNA in Lung Cancer. Int J Mol Sci. 2019 20(7). PMID: 30935143.

62. Ciarletto AM, Narick C, Malchoff CD, Massoll NA, Labourier E, Haugh K, Mireskandari A, Finkelstein SD, Kumar G. Analytical and clinical validation of pairwise microRNA expression analysis to identify medullary thyroid cancer in thyroid fine-needle aspiration samples. Cancer Cytopathol. 2021 129(3): 239249. PMID: 33017868.

63. Kanaan Z, Roberts $H$, Eichenberger MR, Billeter A, Ocheretner G, Pan J, Rai SN, Jorden J, Williford A, Galandiuk S. A plasma microRNA panel for detection of colorectal adenomas: a step toward more precise screening for colorectal cancer. Ann Surg. 2013 258(3): 400-8. PMID: 24022433.

64. Aghdam AM, Amiri A, Salarinia R, Masoudifar A, Ghasemi F, Mirzaei H. MicroRNAs as Diagnostic, Prognostic, and Therapeutic Biomarkers in Prostate Cancer. Crit Rev Eukaryot Gene Expr. 2019 29(2): 127139. PMID: 31679268.

65. Sohel MMH. Circulating microRNAs as biomarkers in cancer diagnosis. Life Sci. 2020 248: 117473. PMID: 32114007
66. Saliminejad K, Khorram Khorshid HR, Ghaffari SH. Why have microRNA biomarkers not been translated from bench to clinic? Future Oncol. 2019 15(8): 801803. PMID: 30652506.

67. Condrat CE, Thompson DC, Barbu MG, Bugnar OL, Boboc A, Cretoiu D, Suciu N, Cretoiu SM, Voinea SC. miRNAs as Biomarkers in Disease: Latest Findings Regarding Their Role in Diagnosis and Prognosis. Cells. 2020 9(2). PMID: 31979244.

68. Calin GA, Sevignani C, Dumitru CD, Hyslop T, Noch E, Yendamuri S, Shimizu M, Rattan S, Bullrich F, Negrini $M$, Croce $C M$. Human microRNA genes are frequently located at fragile sites and genomic regions involved in cancers. Proc Natl Acad Sci U S A. 2004 101(9): 2999-3004. PMID: 14973191.

69. Ferro E, Enrico Bena C, Grigolon S, Bosia C. microRNA-mediated noise processing in cells: A fight or a game? Comput Struct Biotechnol J. 2020 18: 642649. PMID: 32257047.

70. Hamam R, Hamam D, Alsaleh KA, Kassem M, Zaher W, Alfayez M, Aldahmash A, Alajez NM. Circulating microRNAs in breast cancer: novel diagnostic and prognostic biomarkers. Cell Death Dis. 2017 8(9): e3045. PMID: 28880270.

71. Pritchard CC, Cheng HH, Tewari M. MicroRNA profiling: approaches and considerations. Nat Rev Genet. 2012 13(5): 358-69. PMID: 22510765.

72. GalvĂŁo-Lima LJ, Morais AHF, Valentim RAM, Barreto E. miRNAs as biomarkers for early cancer detection and their application in the development of new diagnostic tools. Biomed Eng Online. 2021 20(1): 21. PMID: 33593374.

73. Ozawa PMM, Jucoski TS, Vieira E, Carvalho TM, Malheiros $D$, Ribeiro $E$. Liquid biopsy for breast cancer using extracellular vesicles and cell-free microRNAs as biomarkers. Transl Res. 2020 223: 40-60. PMID: 32413499.

74. Miroshnichenko S, Patutina O. Enhanced Inhibition of Tumorigenesis Using Combinations of miRNA-Targeted Therapeutics. Front Pharmacol. 2019 10: 488. PMID: 31156429.

75. Beg MS, Brenner AJ, Sachdev J, Borad M, Kang YK, Stoudemire J, Smith S, Bader AG, Kim S, Hong DS. Phase I study of MRX34, a liposomal miR-34a mimic, administered twice weekly in patients with advanced solid tumors. Invest New Drugs. 2017 35(2): 180-188. PMID: 27917453.

76. Hanna J, Hossain GS, Kocerha J. The Potential for microRNA Therapeutics and Clinical Research. Front Genet. 2019 10: 478. PMID: 31156715.

77. Mosoyan G, Kraus T, Ye F, Eng K, Crispino JD, Hoffman $\mathrm{R}$, lancu-Rubin $\mathrm{C}$. Imetelstat, a telomerase inhibitor, differentially affects normal and malignant megakaryopoiesis. Leukemia. 2017 31(11): 24582467. PMID: 28270692.

78. Wang X, Hu CS, Petersen B, Qiu J, Ye F, Houldsworth J, Eng K, Huang F, Hoffman R. Imetelstat, a telomerase inhibitor, is capable of depleting myelofibrosis stem and progenitor cells. Blood Adv. 2018 2(18): 2378-2388. PMID: 30242099. 
79. Sheedy P, Medarova Z. The fundamental role of miR10b in metastatic cancer. Am J Cancer Res. 2018 8(9): 1674-1688. PMID: 30323962.

80. Li X, Yu S, Lee D, Kim G, Lee B, Cho Y, Zheng BY, Ke MR, Huang JD, Nam KT, Chen X, Yoon J. Facile Supramolecular Approach to Nucleic-Acid-Driven Activatable Nanotheranostics That Overcome Drawbacks of Photodynamic Therapy. ACS Nano. 2018 12(1): 681688. PMID: 29232105.

81. Reid G, Kao SC, Pavlakis N, Brahmbhatt H, MacDiarmid J, Clarke S, Boyer M, van Zandwijk N. Clinical development of TargomiRs, a miRNA mimic-based treatment for patients with recurrent thoracic cancer. Epigenomics. 2016 8(8): 1079-85. PMID: 27185582.

82. Witten L, Slack FJ. miR-155 as a novel clinical target for hematological malignancies. Carcinogenesis. 2020 41(1): 2-7. PMID: 31711135.
83. Lieberman J. Tapping the RNA world for therapeutics. Nat Struct Mol Biol. 2018 25(5): 357-364. PMID: 29662218.

84. Coutinho MF, Matos L, Santos JI, Alves S. RNA Therapeutics: How Far Have We Gone? Adv Exp Med Biol. 2019 1157: 133-177. PMID: 31342441.

85. Zhupanyn P, Ewe A, BĂL'ch T, Malek A, Rademacher

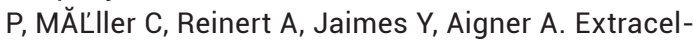
lular vesicle (ECV)-modified polyethylenimine (PEI) complexes for enhanced siRNA delivery in vitro and in vivo. J Control Release. 2020 319: 63-76. PMID: 31866504.

86. Pardi N, Hogan MJ, Porter FW, Weissman D. mRNA vaccines - a new era in vaccinology. Nat Rev Drug Discov. 2018 17(4): 261-279. PMID: 29326426. 